\title{
FREUD E A HISTÓRIA DA ARTE: NOTAS SOBRE ALGUMAS IMPLICAÇÕES METODO- LÓGICAS DO APORTE PSICANALÍTICO
}

Rita de Cássia Lana ${ }^{1}$

Por mais interessante que possa parecer a interpretação da arte segundo o método psicanalítico, desde que Freud publicou "A interpretação dos sonhos" (isto é, fornecendo um arsenal de novos conceitos que pudessem lançar alguma luz sobre o significado de imagens e representações subjetivas), para a história da arte o ponto em questão foi bem estabelecido por Gombrich:

\begin{abstract}
... a questão com respeito a essas pinturas não é que seu criador, a exemplo de todos nós, tem um inconsciente de que se nutrem esses modos arcaicos que simbolização; nem mesmo também que, como todos nós, ele partilha em sua mente as qualidades de Édipo, de Pigmalião, e talvez de Barba-Azul. A questão é que ele se acha numa situação em que seus conflitos particulares adquirem relevância artística. Sem os fatores sociais (...) as necessidades privadas não podia ser transmutado em arte(sic). Nessa transmutação o sentido privado é quase tragado. ${ }^{2}$
\end{abstract}

$\mathrm{Na}$ atualidade, em certos momentos da crítica parece ter-se perdido a advertência de Gombrich e persiste uma versão espúria de análise psicanalítica aplicada à obra de arte, que opera antes como dispositivo de hipertrofia do sujeito e escamoteia o conteúdo potencialmente revolucionário do fenômeno artístico. O presente trabalho tem por objetivo apontar algumas vias teóricas que permitam retomar o problema posto por Gombrich no horizonte da filosofia da arte.

\section{Breves observações sobre alguns pressupostos da abordagem psicanalítica contemporânea da História da arte}

Sem dúvida alguma o método psicanalítico introduzido por Freud trouxe contribuições importantes não apenas para a compreensão da psique do indivíduo e seus aspectos patológicos, mas também para outros campos do conhecimento que procuram estender a análise psicanalítica e suas descobertas a âmbitos culturais e fenômenos coletivos.

Não é o caso de entrar no debate acerca da validade intersubjetiva de observações de casos específicos, pois o terreno do debate está muito mais próximo da esfera da hermenêutica do que de uma teoria analítica mais formalizada. O problema da História da arte surge neste panorama como uma espécie de exemplo paradigmático das dificuldades encontradas em áreas teóricas limítrofes; entre o exame da psicanálise e as teorias sobre a expressão artística abre-se um campo de embate para questões que emergem da tentativa de compreender a obra de arte à luz da teoria freudiana.

Gombrich têm o mérito de haver percebido este ponto e o expressado de forma muito clara, como já foi visto na citação acima; a característica marcante no processo de surgimento de uma obra de arte e a determinação deste status social é primordialmente uma questão de conjuntura social de certos fatores. Ora, a preocupação que move o exercício da psicanálise remete em primeiro lugar a uma estrutura da psique individual e seus símbolos; levar o analisando a tomar consciência de algo que foi reprimido com a finalidade de curar comportamentos patológicos configura o objetivo último da prática psicanalítica. Desta forma, a pretensão de transpor elementos desta área para o campo da História da arte pode

\footnotetext{
${ }^{1}$ Prof ${ }^{a}$. UFSCar, lanarc80@power.ufscar.br

2 GOMBRICH, E.H. A Psicanálise e a História da arte. In: Meditações sobre um cavalinho de pau e outros ensaios sobre a teoria da arte. p. 30-44.
} 
ser considerada problemática e até mesmo temerária, pois pode conduzir a conclusões ideológicas espúrias.

Bastante comum em nossos dias é encontrar artigos jornalísticos e também de caráter científico que versam sobre obras artísticas e literárias nos quais categorias freudianas são utilizadas sem qualquer questionamento sobre sua adequação ao propósito de obter uma crítica do objeto analisado. Basta tomar como exemplo os textos que apareceram na mídia impressa e virtual sobre obras cinematográficas como "Beleza Americana" ou "Matrix", ou mesmo análises que propõe metáforas interpretativas de livros da série "Harry Potter" ou "O código da Vinci", para ficar apenas nos best-sellers que assolam a cultura contemporânea. Há não só uma avidez para buscar episódios biográficos de seus autores como explicação de motivação para a obra, mas um escrutínio doentio dos personagens segundo algo que poderia ser qualificado como "psicanálise de botequim".

É bem conhecido o interesse que o próprio Freud mantinha por objetos artísticos e seus escritos estéticos; a diferença entre estes textos e o que hoje se observa sair da lavra de alguns críticos de arte está em que o pai da psicanálise conhecia sobejamente as limitações de seu método e evitava propor conclusões que levassem a compreender a obra de arte exclusivamente como uma espécie de subproduto de complexos, neuroses ou qualquer outra patologia que afetasse seu autor.

Entretanto, seria ingênuo pensar que se trata somente de um caso de maus intérpretes da teoria psicanalítica para explicar o "esquecimento" da advertência de Gombrich. Ao recordar que a teoria psicanalítica contém um potencial explicativo para determinados fatores presentes na interpretação da obra de arte $^{3}$, deve-se ter em mente também outros textos de Freud que buscam explicar a gênese sócio-individual dos mecanismos de repressão e sublimação, como é o caso de "O mal-estar na civilização" e a leitura do fenômeno religioso em "O Futuro de uma Ilusão".

Uma das características da cultura contemporânea é a apropriação de obras de arte consagradas ao longo da história pela indústria cultural, com o conseqüente empobrecimento no processo de sua resignificação pela mídia, visando colocá-la no circuito de imagens e representações ditas pós-modernas e apresentar ao público uma pseudodesalienação cultural.

Ora, nesse circuito cultural-ideológico perverso são mobilizados uma série de dispositivos discursivos que necessitam mostrar-se dotados de autoridade competente, para convencer a opinião pública de que é possível um acesso fácil aos chamados bens culturais. Propõe-se, então, uma versão rala de interpretação psicanalítica do significado das obras de arte, que passa por ter uma profundidade teórica que é apenas ilusória. Desta maneira, as obras de arte e a teoria psicanalítica são despojadas de seu potencial crítico da realidade, surgindo uma subcrítica de arte que impera nos meios de comunicação contemporâneos.

Como se pode notar até aqui, poder-se-ia descrever o uso de uma "sub-versão" da teoria psicanalítica pela indústria cultural como um desvirtuar de uma ferramenta metodológica no contexto contemporâneo da História da arte. Seria este um argumento decisivo, ao lado daquele dado por Gombrich para recomendar aos historiadores e críticos de arte um descarte da teoria psicanalítica como instrumento de interpretação do fenômeno artístico?

Tal não só seria descabido, mas no contexto atual impraticável, principalmente ao considerar que a colaboração entre história da arte e teoria da psicanálise já produziu

${ }^{3}$ GOMBRICH, E.H. Metáforas visuais de valor na arte. Opus cit., p.12-29

${ }^{4}$ FREUD, S. Obras completas. 
abordagens profícuas e novos olhares sobre os produtos da arte e da cultura em geral, e de fato é possível constatar que muitas das observações feitas por Freud foram incorporadas por teóricos e historiadores da arte no desenvolvimento de seus trabalhos.

Para citar um exemplo bem conhecido, basta lembrar a obra "Eros e civilização", na qual filosofia, história da cultura e psicanálise não só se encontram e dialogam criativamente, mas também se delineia a percepção crítica de usos indevidos da matriz freudiana e a percepção de que a teoria psicanalítica possui uma trajetória enquanto paradigma de interpretação da sociedade que não deve ser ignorada. Graças a estas abordagens críticas, advindas do âmbito propriamente filosófico, é que se pode atentar sobre alguns mal-entendidos que contribuem para a instrumentalização do patrimônio teórico freudiano pela indústria cultural.

Nesse sentido é que se compreende que assim como na obra de arte, o conteúdo social da teoria de Freud sobre a promessa de felicidade não realizada pela civilização possui uma dimensão revolucionária; esta é freqüentemente esquecida ao sublinhar-se aspectos da terapia em detrimento do que Marcuse chamou "metapsicologia" de Freud", o que constitui um empobrecimento de viés ideológico da herança freudiana.

\section{Alguns elementos para uma compreensão crítica da relação entre a teoria freudiana e a história da arte contemporânea}

Postas estas considerações iniciais, permanece o desafio de buscar uma recuperação da promissora relação entre psicanálise e história da arte no horizonte do mundo hodierno. Como já se antevê, há muitas questões a serem levadas em conta e que, se por um lado tornam difícil uma resposta imediata, por outro atuam como sinalizadoras de que ignorá-las é permanecer refém das ideologias hegemônicas na vida contemporânea.

Assim, problemas referentes ao gosto e aos juízos estéticos demandam a contribuição de uma história da arte informada pelas categorias teóricas psicanalíticas, que seja capaz de registrar os sinais do subjetivismo exacerbado na produção artística contemporânea e interpretá-los criticamente. A relação entre o fazer artístico e a recepção pública das obras se ressente de uma espécie de pudor de falar sobre aspectos intersubjetivos inerentes ao circuito cultural e à formação de um público das artes no mundo atual - como se a dimensão do sujeito tivesse ocupado todos os espaços possíveis para interpretação da obra de arte.

Seria preciso lembrar que a postura solipsista, elevada a ápice da racionalidade no método pelo projeto iluminista, acaba por estabelecer um entendimento do mundo que desconhece, ou melhor, que se nega a reconhecer tudo que não lhe seja idêntico: configurase como um totalitarismo do pensamento do Mesmo, conforme apontara Adorno ${ }^{7}$.

Aqui se chega àquela outra fronteira que é muito maior, que ultrapassa o embate método psicanalítico/ história da arte: a beira do abismo do não-eu, de tudo aquilo que está fora do alcance da racionalidade, que não se expressa, pois o expressar significa ser convertido no idêntico pela racionalização sistemática da modernidade. Seu aspecto mais evidente nos dias de hoje é a intolerância ao que se recusa a ser incorporado nessa lógica. Em que medida o fazer artístico, hoje, não compactua com esse processo? Eis uma das grandes questões para a história da arte e a crítica contemporâneas.

\footnotetext{
${ }^{5}$ MARCUSE, H. Eros e civilização. Uma interpretação filosófica do pensamento de Freud.

${ }^{6}$ MARCUSE, H. Idem, p. 212.

7 ADORNO, T.W. Dialética Negativa.
} 
A simples admissão da existência de algo que não é idêntico constitui uma fonte de angústia para o sujeito; a positividade que ele detém deve ser absoluta, inquestionável, como dizem os frankfurtianos:

A imanência pura do positivamente, seu produto último, é algo como um tabu universal. Lá fora não deve haver mais nada, pois a mera representação do lá fora é a verdadeira fonte de angústia ${ }^{8}$.

Ocorre que esta fronteira da racionalidade é solicitada a se expandir diante do alcance planetário que a ciência têm hoje; sua expansão, conforme dizia Benjamin, é um monumento à barbárie, pois remitologiza o mundo para assegurar seu domínio, para manter o "mundo administrado", malgrado a sensação de perda, o mal-estar cada vez mais agudo nos indivíduos. A arte contemporânea, nesse panorama, seria capaz de buscar uma forma negativa de expressão, já que toda representação positiva significa uma rendição e uma entrada no sistema do idêntico? Poder-se-á ainda empreender uma busca pela apresentação (Darstellung) em lugar de anuir ao sistema cultural totalitário?

Para colaborar na resposta a estas questões, é preciso pensar que a meta a ser perseguida pela crítica e pela história da arte também supõe o aceite do desafio lançado por Adorno: que Auschwitz não se repita; que a arte, a poesia a ser feita só será moralmente aceitável se recusar-se a partilhar o sistema cultural que produziu a Shoah. Em outras palavras, que não se desconheça a dimensão coletiva, intersubjetiva e nem se busque a mera aniquilação do Outro ou sua conversão ao idêntico. Mas isto está em absoluta consonância com a advertência de Gombrich, de que sem os fatores sociais não se explicará a relevância da obra de arte, e com sua honesta admissão dos limites da crítica, pois:

Isso porque, para solucionar essa questão - seja dito com toda humildade

- a psicanálise não é competente; mas tampouco o é a História da Arte9.

\section{Referências bibliográficas}

ADORNO, T.W. Dialética Negativa. Madrid: Taurus, 1975.

/ HORKHEIMER, M. Dialética do esclarecimento. Rio de Janeiro: J. Zahar, 1985.

FREUD, S. Obras completas, vol. XXI. Rio de Janeiro: Imago, 1974.

GOMBRICH, E.H. A Psicanálise e a História da arte. In: Meditações sobre um cavalinho de pau e outros ensaios sobre a teoria da arte. São Paulo: Edusp, 1999

MARCUSE, H. Eros e civilização. Uma interpretação filosófica do pensamento de Freud. $6^{a}$. Ed. Rio de Janeiro: Zahar, 1975.

\footnotetext{
${ }^{8}$ HORKHEIMER, M., ADORNO, T.W. O conceito de esclarecimento. Opus cit.

${ }^{9}$ GOMBRICH, E.H. Opus cit., p.44.
} 